\title{
Variable Order Block Method for Solving Second Order Ordinary Differential Equations
}

(Kaedah Blok Peringkat Berubah untuk Penyelesaian Persamaan Pembezaan Biasa Peringkat Kedua)

\author{
ZARINA BIBI IBRAHIM, NOORAINI ZAINUDDIN*, KHAIRIL ISKANDAR OTHMAN, \\ MOHAMED SULEIMAN \& ISKANDAR SHAH MOHD ZAWAWI
}

\begin{abstract}
This paper proposed 2-point block backward differentiation formulas (BBDF) of order 3, 4, and 5 for direct solution of second order ordinary differential equations. These methods were derived via backward difference interpolation polynomial with two solutions are produced simultaneously at each step. All the three different orders of 2-point BBDF is implemented in variable order scheme. The scheme utilizes the local truncation error, which is generated by the single order of 2-point BBDF method. Numerical results are presented to illustrate the validity of the proposed scheme.
\end{abstract}

Keywords: Block method; initial value problem; second order ODEs; variable order

\section{ABSTRAK}

Kertas ini membangunkan formula 2-titik blok pembezaan kebelakang (FBPK) peringkat 3, 4, dan 5 untuk menyelesaikan persamaan pembezaan biasa peringkat kedua. Kaedah ini diterbitkan melalui polinomial interpolasi beza kebelakang dengan dua penyelesaian diberikan secara serentak untuk setiap langkah. Ketiga-tiga peringkat 2-titik FBPK dijalankan dengan skema peringkat berubah. Skema ini menggunakan ralat pangkasan setempat, yang dijanakan oleh setiap peringkat kaedah 2-titik FBPK. Keputusan berangka ditunjukkan untuk menggambarkan kesahihan skema yang dicadangkan.

Kata kunci: Kaedah blok; masalah nilai awal; PBB peringkat kedua; peringkat berubah

\section{INTRODUCTION}

In recent years, studies on higher order Ordinary Differential Equations (ODEs) have been done vigorously. Some examples of higher order ODEs can be seen in the orbit equations, satellite tracking and fluid dynamics. The popular approach to solve higher order ODEs is by reducing it into a system of first order. This approach will increase the number of equations to $d n$, where $d$ and $n$ are, respectively, defined as order and number of equations in higher order form. The equations were later solved by the first order solver, for example the method based on backward differentiation formula (Ibrahim et al. 2007).

This paper considered second order ODEs as follows,

$$
y^{\prime \prime}=f\left(x, y, y^{\prime}\right), y(a)=y_{0}, y^{\prime}(a)=y_{0}^{\prime}
$$

in the interval $x \in[a, b]$.

The direct approach to higher order ODEs is believed to offer speed and accuracy advantages (Gear 1967). There are various direct solvers discussed in the literature. For instance, Runge-Kutta method (Ismail et al. 2016), Runge-Kutta-Nyström method (Chawla \& Sharma 1985), hybrid method (Jator 2010; Kambo et al. 1983), additive parameters method (Sesappa Rai \& Ananthakrishnaiah 1996), and block method (Chien et al. 2018; Ismail et al. 2018; Waeleh \& Majid 2017; Zainuddin et al. 2014), to name a few. Block method were first introduced by Milne (1953) as a means of obtaining starting values for predictor-corrector schemes. Fatunla (1991) then proposed the block method that directly solve special form of (1). The derivation was carried out based on the order definition which ensure the method is of order three or four. Since then an enormous amount of studies has been done on solving (1) or its special form directly in block term (Jator 2013, 2010; Jator \& Li 2009; Ibrahim et al. 2012; Ismail et al. 2018; Sagir 2013; Waeleh \& Majid 2017; Zainuddin et al. 2014). Our intention is to derive the 2-point block backward differentiation formulas (BBDF) using variable order scheme for solving (1). The proposed method solves such problem directly and produce two approximated solutions concurrently for each successful integration step.

\section{DERIVATION OF 2-POINT BLOCK BACKWARD DIFFERENTIATION FORMULAS}

The derivation of the 2-point block backward differentiation formulas (BBDF) is based on backward difference interpolation polynomial. The approximation at two points, i.e. $x_{n+1}$ and $x_{n+2}$ are computed simultaneously by using the values of the preceding blocks (Figure 1). To apply the variable order scheme, three different orders of 2-point BBDF is derived. As the order of 2-point BBDF is distinguished by the number of interpolating points, three different back values are used in derivation step. 


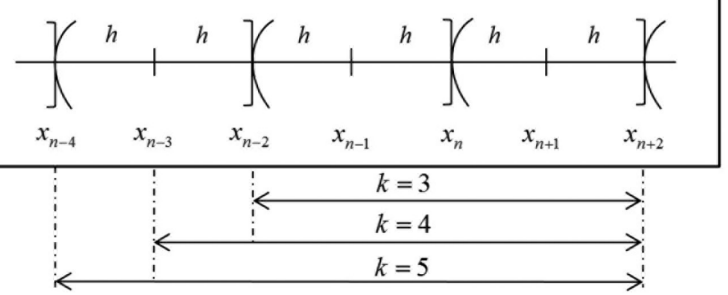

FIGURE 1. The interpolating point for 2-point BBDF

The interval $[a, b]$ is first divided into a series of block, with each block containing two points. The formula of $k, k=3,4,5$ back values 2-point BBDF are derived from the set of interpolating points $\left\{\left(x_{n-2}, y_{n-2}\right), \ldots,\left(x_{n+2}, y_{n+2}\right)\right\}$, $\left\{\left(x_{n-3}, y_{n-3}\right), \ldots,\left(x_{n+2}, y_{n+2}\right)\right\}$ and $\left\{\left(x_{n-4}, y_{n-4}\right), \ldots,\left(x_{n+2}\right.\right.$, $\left.\left.y_{n+2}\right)\right\}$, respectively. Subsequently, the backward difference interpolation polynomial, $P_{k}(x)$ which interpolates equation (1) at $k$ back values is given by:

$$
P_{k}(x)=\sum_{m=0}^{k+1}(-1)^{m}\left(\begin{array}{l}
-s \\
m
\end{array}\right) \nabla^{m} y_{n+2},
$$

where $s=\frac{x-x_{n+2}}{h}$.

The corrector formulas of $y_{n+1}^{\prime}$ and $y_{n+1}$ are defined by differentiating (2) once and twice, i.e. $j=1,2$ at $x=x_{n+1}$ to obtain:

$$
\begin{aligned}
h^{j} P_{k, n+1}^{(j)}(x) & =\left.\sum_{m=0}^{k+1}(-1)^{m} \frac{d^{j}}{d x^{j}}\left(\begin{array}{l}
-S \\
m
\end{array}\right) \nabla^{m} y_{n+2}\right|_{x=x_{n+1}} \\
& =\left.\sum_{m=0}^{k+1}(-1)^{m} \frac{d^{j}}{d s^{j}}\left(\begin{array}{l}
-s \\
m
\end{array}\right) \nabla^{m} y_{n+2}\right|_{s=-1} \\
& =\sum_{m=0}^{k+1} \delta_{j, m} \nabla^{m} y_{n+2}
\end{aligned}
$$

where $\delta_{j, m}=\left.(-1)^{m} \frac{d^{j}}{d s^{j}}\left(\begin{array}{l}-s \\ m\end{array}\right)\right|_{s=-1}, j=1,2$.

The method of generating function is used for finding the general relation of the coefficients $\delta_{j, m}, j=1,2$. The resulting coefficients of $\delta_{j, m}$, for $j=1$ and $j=2$ are tabulated as follows:

$$
j=1 ; \quad \delta_{1, m}= \begin{cases}0, & m=0, \\ 1, & m=1, \\ \left(\frac{1}{m}-\frac{1}{m-1}\right), & m=2,3,4, \cdots\end{cases}
$$

$$
j=2 ; \delta_{2, m}= \begin{cases}0, & m=0,1 \\ 1, & m=2 \\ \sum_{p=1}^{m-1}\left(\frac{1}{p}\right)\left(\frac{1}{m-p}\right)-\sum_{p=1}^{m-2}\left(\frac{1}{p}\right)\left(\frac{1}{m-1-p}\right), & m=3,4, \cdots\end{cases}
$$

The corrector formulas at the point $x=x_{n+1}$ which are $y_{n+1}^{\prime}$ and $y_{n+1}$ are generated respectively by substituting $\delta_{1, m}$ and $\delta_{2, m}$ into (3). For the formulas of 2-point BBDF with $k$ $=3$, the interpolation points $\left\{\left(x_{n-2}, y_{n-2}\right), \ldots,\left(x_{n+2}, y_{n+2}\right)\right\}$ are used. Therefore, the derivation of $y_{n+1}^{\prime}$ is derived with $k=3$ and $j=1$. The respective coefficients of $\delta_{1, m}$ are substituted into (3) as follows:

$$
\begin{aligned}
h P_{3, n+1}^{\prime}(x) & =\sum_{m=0}^{4} \delta_{1, m} \nabla^{m} y_{n+2}, \\
& =\delta_{1,0} \nabla^{0} y_{n+2}+\delta_{1,1} \nabla^{1} y_{n+2}+\delta_{1,2} \nabla^{2} y_{n+2}+\delta_{1,3} \nabla^{3} y_{n+2}+\delta_{1,4} \nabla^{4} y_{n+2}, \\
& =\frac{1}{4} y_{n+2}+\frac{5}{6} y_{n+1}-\frac{3}{2} y_{n}+\frac{1}{2} y_{n-1}-\frac{1}{12} y_{n-2} .
\end{aligned}
$$

Letting $P_{3, n+1}^{\prime}=y_{n+1}^{\prime}$, the first corrector formula for 2-point BBDF with $k=3$ is defined. The corrector formula of $y_{n+1}$ is derived by using similar approach as (6) by substituting $\delta_{2, m}$ with $k=3$ and $j=2$ into (3).

$$
\begin{aligned}
h^{2} P_{3, n+1}^{\prime \prime}(x) & =\sum_{m=0}^{4} \delta_{2, m} \nabla^{m} y_{n+2}, \\
& =\delta_{2,0} \nabla^{0} y_{n+2}+\delta_{2,1} \nabla^{1} y_{n+2}+\delta_{2,2} \nabla^{2} y_{n+2}+\delta_{2,3} \nabla^{3} y_{n+2}+\delta_{2,4} \nabla^{4} y_{n+2}, \\
& =\frac{11}{12} y_{n+2}-\frac{5}{3} y_{n+1}+\frac{1}{2} y_{n}+\frac{1}{3} y_{n-1}-\frac{1}{12} y_{n-2} .
\end{aligned}
$$

Following equation (1), $P_{3, n+1}^{\prime \prime}=y_{n+1}^{\prime \prime}=f_{n+1}$ and after we simplified the term for $y_{n+1}$, the corrector formula for $y_{n+1}$ is as follows:

$$
y_{n+1}=\frac{11}{20} y_{n+2}+\frac{3}{10} y_{n}+\frac{1}{5} y_{n-1}-\frac{1}{20} y_{n-2}-\frac{3}{5} h^{2} f_{n+1} .
$$

The corrector formulas of $y_{n+1}^{\prime}$ and $y_{n+1}$ for $k=4$ and $k=5$ are derived by applying similar approaches as (6) and (7).

For the derivation of the corrector formula at the second point, i.e. $x=x_{n+2}$, (2) is differentiated once and twice, i.e. $j=1,2$ with $x=x_{n+2}$.

$$
h^{j} P_{k, n+2}^{(j)}(x)=\left.\sum_{m=0}^{k+1}(-1)^{m} \frac{d^{j}}{d x^{j}}\left(\begin{array}{l}
-S \\
m
\end{array}\right) \nabla^{m} y_{n+2}\right|_{x=x_{n+2}}=\sum_{m=0}^{k+1} \gamma_{j, m} \nabla^{m} y_{n+2} .
$$

Subsequently, the formulas for the coefficients $\gamma_{j, m}$, $j=1,2$ after we adopted the generating function strategy are as follow;

$$
\begin{aligned}
& j=1 ; \quad \gamma_{1, m}= \begin{cases}0, & m=0, \\
\frac{1}{m}, & m=1,2,3, \cdots\end{cases} \\
& j=2 ; \quad \gamma_{2, m}= \begin{cases}0, & m=0,1, \\
\sum_{p=1}^{m-1}\left(\frac{1}{p}\right)\left(\frac{1}{m-p}\right), & m=3,4, \cdots .\end{cases}
\end{aligned}
$$


The corrector formulas of $y_{n+2}^{\prime}$ and $y_{n+2}$ are then easily derived by applying the similar approach as to obtain the corrector formulas of $y_{n+1}^{\prime}$ and $y_{n+1}$. The formulas of 2-point BBDF for $k=3,4,5$ are tabulated in Table 1 .

\section{CONVERGENCE AND STABILITY ANALYSIS}

The basic properties of any linear multistep method (LMM) comprises the convergence, consistency and zero stability. The convergence of the LMM is confirmed if it is consistent and zero-stable. To accommodate the discussion on the convergence of the proposed method, it is convenience to express it in its general form.

The standard LMM for the second order ODEs can be written as:

$$
\sum_{j=0}^{k} \alpha_{j} y_{n+j}=h \sum_{j=0}^{k} \beta_{j} y_{n+j}^{\prime}+h^{2} \sum_{j=0}^{k} \gamma_{j} f_{n+j}
$$

and $f_{n+j}=y_{n+j}^{\prime \prime}$.
Following (12), the 2-point BBDF can be written in matrix difference equation as follows:

$$
\sum_{j=0}^{k+1} A_{j} y_{n+j-(k-1)}=h \sum_{j=0}^{k+1} B_{j} y_{n+j-(k-1)}^{\prime}+h^{2} \sum_{j=0}^{k+1} D_{j} f_{n+j-(k-1)},
$$

where $A_{j}, B_{j}$ and $D_{j}$ are $m r$ by 1 matrices with $m$ denotes the $m$-th order ODEs and $r$ is the block size. The linear difference associated with (13) is given by:

$$
\begin{aligned}
L[y(x) ; h]= & \sum_{j=0}^{k+1} A_{j} y(x+h(j-(k-1)))- \\
& h \sum_{j=0}^{k+1} B_{j} y^{\prime}(x+h(j-(k-1)))- \\
& h^{2} \sum_{j=0}^{k+1} D_{j} f(x+h(j-(k-1))) .
\end{aligned}
$$

By expanding the functions $y(x+h(j-(k-1))), y^{\prime}(x$ $+h(j-(k-1)))$ and $f(x+h(j-(k-1)))$ about the point

TABLE 1 . The 2-point BBDF for $k=3,4,5$

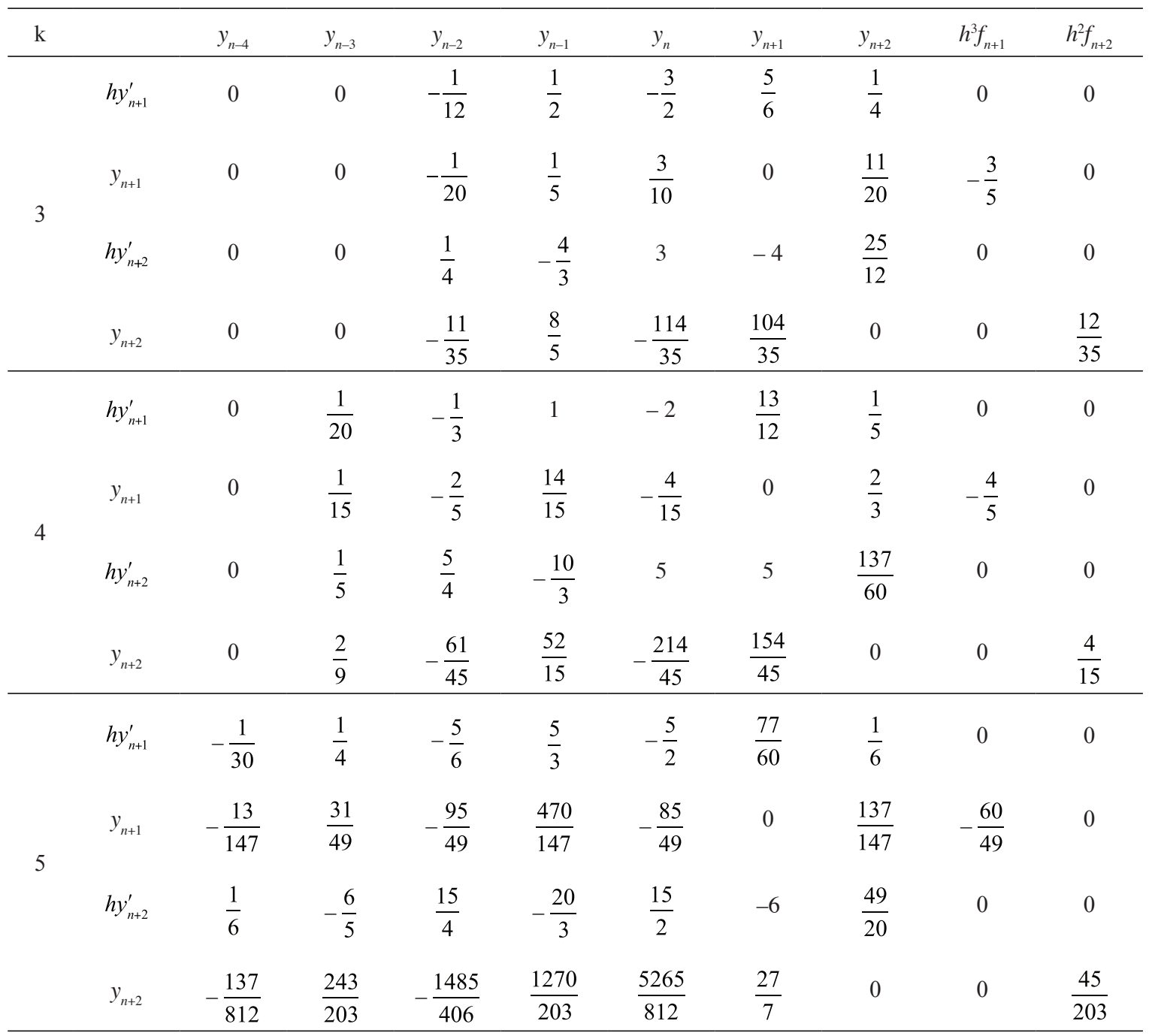


$x$ by using Taylor series, and by collecting the terms in power of $h$ gives:

$L[y(x) ; h]=\sum_{j=0}^{k+1}\left[C_{0} y(x)+C_{1} h y^{\prime}(x)+C_{2} h^{2} y^{\prime \prime}(x)+\cdots+C_{q} h^{q} y^{(q)}(x)+\cdots\right]$,

where the constant $C_{q}$ is defined as:

$$
C_{q}=\sum_{j=0}^{k}\left(\frac{j^{q}}{q !} A_{j}-\frac{j^{q-1}}{(q-1) !} B_{j}-\frac{j^{q-2}}{(q-2) !} D_{j}\right), \quad q=0,1,2,3,4 \cdots .
$$

$A_{j}, B_{j}$ and $D_{j}$ are equivalent to coefficients of $y_{n+j-(k-1)}, y_{n+j-(k-1)}^{\prime}$ and $f_{n+j-(k-1)}$, respectively.

According to Henrici (1962), the LMM for second order ODEs has order $p$ if $C_{0}=C_{1}=\ldots=C_{p+1}=0$, and $C_{p+2} \neq 0$. $C_{p+2}$ is the error constant. Applying methods in Table 1 into (13), the order and error constant for each $k$ are tabulated as in Table 2.

Therefore, the 2-point BBDF with $k=3,4,5$ are order of $3,4,5$, respectively.

To justify the convergence of methods in Table 1 , the following definition is referred.

Definition 1 The block method (13) is said to be consistent if it has order $p \geq 1$.

Following this, one of the criteria for convergence is assured as all the three derived methods has order greater than one. To guarantee the zero stability of the proposed method, the following definitions are referred.

Definition 2 The block method is zero-stable provided the roots $R_{j}$ of its first characteristic polynomial satisfy $\left|R_{j}\right| \leq 1$, $j=1(1) k$ and for those roots with $\left|R_{j}\right|=1$, the multiplicity must not exceed 2 (Fatunla 1991).

Definition 3 The LMM is said to be absolutely stable if the roots of the characteristic equation are in moduli less than one for all values of the step length $h$.

The zero stability of the 2-point BBDF is determined by imposing the following test equation into Table 1 .

$$
y^{\prime \prime}=\theta y^{\prime}+\mu y, \quad \theta, \mu \in \Re .
$$

Subsequently, the coefficients are rearranged and rewritten in the matrix form as follows:

$$
A_{0} z_{m}=\sum_{i=1}^{3} A_{i} z_{m-i}, \quad n=2 m
$$

where $A_{0}$ and $A_{i}$ are 4 by 4 matrices.

$$
\begin{aligned}
& z_{m}=\left[\begin{array}{l}
y_{n+2}^{\prime} \\
y_{n+2} \\
y_{n+1}^{\prime} \\
y_{n+1}
\end{array}\right]=\left[\begin{array}{l}
y_{2 m+2}^{\prime} \\
y_{2 m+2} \\
y_{2 m+1}^{\prime} \\
y_{2 m+1}
\end{array}\right], \\
& z_{m-1}=\left[\begin{array}{l}
y_{n}^{\prime} \\
y_{n} \\
y_{n-1}^{\prime} \\
y_{n-1}
\end{array}\right]=\left[\begin{array}{l}
y_{2 m}^{\prime} \\
y_{2 m} \\
y_{2 m-1}^{\prime} \\
y_{2 m-1}
\end{array}\right]=\left[\begin{array}{l}
y_{2(m-1)+2}^{\prime} \\
y_{2(m-1)+2} \\
y_{2(m-1)+1}^{\prime} \\
y_{2(m-1)+1}
\end{array}\right], \\
& z_{m-2}=\left[\begin{array}{l}
y_{n-2}^{\prime} \\
y_{n-2}^{\prime} \\
y_{n-3}^{\prime}
\end{array}\right]=\left[\begin{array}{l}
y_{2 m-2}^{\prime} \\
y_{2 m-2} \\
y_{2 m-3}^{\prime} \\
y_{2 m-3}
\end{array}\right]=\left[\begin{array}{l}
y_{2(m-2)+2}^{\prime} \\
y_{2(m-2)+2} \\
y_{2(m-2)+1}^{\prime} \\
y_{2(m-2)+1}
\end{array}\right], \\
& z_{m-3}=\left[\begin{array}{l}
y_{n-4}^{\prime} \\
y_{n-4} \\
y_{n-5}^{\prime} \\
y_{n-5}
\end{array}\right]=\left[\begin{array}{l}
y_{2 m-4}^{\prime} \\
y_{2 m-4} \\
y_{2 m-5}^{\prime} \\
y_{2 m-5}
\end{array}\right]=\left[\begin{array}{l}
y_{2(m-3)+2}^{\prime} \\
y_{2(m-3)+2} \\
y_{2(m-3)+1}^{\prime} \\
y_{2(m-3)+1}
\end{array}\right] .
\end{aligned}
$$

\begin{tabular}{|c|c|c|c|c|c|}
\hline Method & Order $p$ & \multicolumn{4}{|c|}{ Error constant $C_{p+2}$} \\
\hline$k=3$ & $\left(\begin{array}{llll}3 & 3 & 3 & 3\end{array}\right)^{T}$ & $\frac{1}{20}$ & $-\frac{1}{20}$ & $-\frac{1}{5}$ & $-\frac{2}{7}$ \\
\hline$k=4$ & $\left(\begin{array}{llll}4 & 4 & 4 & 4\end{array}\right)^{T}$ & $\frac{1}{20}$ & $-\frac{33}{225}$ & $-\frac{1}{6}$ & $-\frac{137}{675}$ \\
\hline$k=5$ & $\left(\begin{array}{llll}5 & 5 & 5 & 5\end{array}\right)^{T}$ & $\frac{1}{42}$ & $-\frac{11}{147}$ & $-\frac{1}{7}$ & $-\frac{9}{58}$ \\
\hline
\end{tabular}

and

The determinant of the matrix $A_{0} R^{3}-\sum_{i=1}^{3} A_{i} R^{3-i}$ implying the stability function, $L\left(R, H_{1}, H_{2}\right)$ of the method. Setting $H_{1}=h^{2} \mu$ and $H_{2}=h \theta$, the stability function of the 2-point $\mathrm{BBDF}$ for $\mathrm{k}=3,4,5$ are obtained.

TABLE 2. Order and error constant for 2-point BBDF 


$$
\begin{aligned}
k=3 ; \quad L\left(R, H_{1}, H_{2}\right)= & \frac{1}{350} R^{5}\left(6+3 H_{2}-H_{2}^{2}\right)- \\
& \frac{3}{350} R^{6}\left(78+31 H_{2}-15 H_{2}^{2}+\right. \\
& \left.H_{1}\left(-22+6 H_{2}\right)\right)+ \\
& \frac{3}{350} R^{7}\left(150+51 H_{2}^{2}+236 H_{1}-\right. \\
& \left(H_{2}\left(85+84 H_{1}\right)\right) \\
& \frac{1}{350} R^{8}\left(-222-72 H_{1}^{2}+345 H_{2}-\right. \\
& \left.197 H_{2}^{2}-90 H_{1}-210 H_{1} H_{2}\right) .
\end{aligned}
$$

$$
\begin{aligned}
k=4 ; L\left(R, H_{1}, H_{2}\right)= & \frac{1}{3375} R^{4}\left(-5-14 H_{2}+3 H_{2}^{2}\right)+ \\
& \frac{4}{3375} R^{5}\left(-115+21 H_{2}+2 H_{2}^{2}\right)- \\
& \frac{2}{1125} R^{6}\left(565+668 H_{2}-219 H_{2}^{2}+\right. \\
& \left.4 H_{1}\left(-155+39 H_{2}\right)\right)+ \\
& \frac{4}{3375} R^{7}\left(2045-445 H_{2}+294 H_{2}^{2}-\right. \\
& \left.180 H_{1}\left(-19+6 H_{2}\right)\right)+ \\
& \frac{1}{3375} R^{8}\left(-4325-720 H_{1}^{2}+5718 H_{2}-\right. \\
& \left.2501 H_{2}^{2}-24 H_{1}\left(-75+101 H_{2}\right)\right) .
\end{aligned}
$$

$$
\begin{aligned}
k=5 ; L\left(R, H_{1}, H_{2}\right)= & \frac{1}{39788} R^{7}\left(-35+105 H_{2}-18 H_{2}{ }^{2}\right)+ \\
& \frac{5}{39788} R^{8}\left(164-121 H_{2}+15 H_{2}{ }^{2}\right)- \\
& \frac{5}{19894} R^{9}\left(4301+1045 H_{2}-450 H_{2}{ }^{2}+\right. \\
& \left.6 H_{1}\left(-137+30 H_{2}\right)\right)- \\
& \frac{5}{19894} R^{10}\left(1954+14415 H_{2}-3825 H_{2}{ }^{2}+\right. \\
& \left.+18 H_{1}\left(-1021+240 H_{2}\right)\right)+ \\
& \frac{5}{39788} R^{11}\left(33001+6709 H_{2}+390 H_{2}{ }^{2}-\right. \\
& \left.60 H_{1}\left(-1147+330 H_{2}\right)\right)+ \\
& \frac{1}{39788} R^{12}\left(-103240-10800 H_{1}^{2}+121555 H_{2}-\right. \\
& \left.44757 H_{2}^{2}-420 H_{1}\left(-95+96 H_{2}\right)\right) .
\end{aligned}
$$

Zero stability is concerned with the stability of LMM as $h$ approaching zero. As $h$ tends to 0 , the coefficients $H_{1}, H_{2}$ in (19), (20), and (21) tends to 0. Subsequently, the first characteristic polynomials for the 2-point BBDF are interpreted as:

$$
k=3 ; \quad \frac{3}{175} R^{5}-\frac{117}{175} R^{6}+\frac{9}{7} R^{7}-\frac{111}{175} R^{8}=0,
$$

$$
\begin{gathered}
k=4 ; \quad-\frac{1}{675} R^{4}-\frac{92}{675} R^{5}-\frac{226}{225} R^{6}+\frac{1636}{675} R^{7}-\frac{173}{135} R^{8}=0, \\
k=5 ; \quad-\frac{5}{5684} R^{7}+\frac{205}{9947} R^{8}-\frac{21505}{19894} R^{9}-\frac{4885}{9947} R^{10} \\
+\frac{165005}{39788} R^{11}-\frac{890}{343} R^{12}=0 .
\end{gathered}
$$

By solving (22), (23) and (24), the roots $R$ are obtained as follows:

$$
\begin{aligned}
k=3 ;|\mathrm{R}|= & 0,0,0,0,0,0.0270270,1,1 . \\
k=4 ;|\mathrm{R}|= & 0,0,0,0,0.0967175,0.0119531,1,1 . \\
k=5 ;|\mathrm{R}|= & 0,0,0,0,0,0,0,0.4209068,0.0283803, \\
& 0.0283803,1,1 .
\end{aligned}
$$

Following this, the zero stability of the 2-point BBDF is guaranteed since all the roots of first characteristic polynomials satisfy the Definition 2.

\section{IMPLEMENTATION OF VARIABLE ORDER 2-POINT BBDF}

This section describes the implementation of 2-point BBDF method using modified Newton iteration technique. The 2-point BBDF can be generalized as:

$$
\begin{aligned}
& y_{n+1}=\alpha_{1} h^{2} f_{n+1}+\beta_{1} y_{n+2}+W_{1}, \\
& y_{n+2}=\alpha_{2} h^{2} f_{n+2}+\beta_{2} y_{n+1}+W_{2}, \\
& h y_{n+1}^{\prime}=\theta_{1} y_{n+1}+\omega_{1} y_{n+2}+V_{1}, \\
& h y_{n+2}^{\prime}=\theta_{2} y_{n+1}+\omega_{2} y_{n+2}+V_{2},
\end{aligned}
$$

where $W_{1}, W_{2}, V_{1}, V_{2}$ are the back values. As the 2-point BBDF is a block method, it required simultaneous implementation of formulas at the points $x_{n+1}$ and $x_{n+2}$. We apply the same derivation techniques of the Newton iteration matrices as proposed in Ibrahim et al. (2012). The notations $i$ and $i-1$ are used to differentiate the number of iterations. Given as follows are the corresponding matrices that need to be solved in the iteration process.

$$
\begin{gathered}
\left(\begin{array}{cc}
1-\alpha_{1} h^{2} J_{n+1}-\alpha_{1} \theta_{1} h J_{n+1}^{\prime} & -\beta_{1}-\alpha_{1} \omega_{1} h J_{n+1}^{\prime} \\
-\beta_{2}-\alpha_{2} \theta_{2} h J_{n+2}^{\prime} & 1-\alpha_{2} h^{2} J_{n+2}-\alpha_{2} \omega_{2} h J_{n+2}^{\prime}
\end{array}\right)\left(\begin{array}{c}
e_{n+1} \\
e_{n+2}
\end{array}\right)^{(i)} \\
=\left(\begin{array}{c}
-y_{n+1}^{(i-1)}+\alpha_{1} h^{2} f_{n+1}^{(i-1)}+\beta_{1} y_{n+2}^{(i-1)}+W_{1} \\
-y_{n+2}^{(i-1)}+\alpha_{2} h^{2} f_{n+2}^{(i-1)}+\beta_{2} y_{n+1}^{(i-1)}+W_{2}
\end{array}\right),
\end{gathered}
$$

and followed by

$$
\left(\begin{array}{c}
e_{n+1}^{\prime} \\
e_{n+2}^{\prime}
\end{array}\right)^{(i+1)}=h\left(\begin{array}{ll}
\theta_{1} & \omega_{1} \\
\theta_{2} & \omega_{2}
\end{array}\right)\left(\begin{array}{l}
e_{n+1} \\
e_{n+2}
\end{array}\right)^{(i+1)} .
$$


$e_{n+1, n+2}^{(i)}$ and $e_{n+1, n+2}^{(i)}$ are the increments that will be added to the old iterations of $y_{n+1, n+2}^{(i-1)}$ and $y_{n+1, n+2}^{(i-1)}$, respectively. These increments are solved by LU decomposition. $J_{n+1, n+2}$ and $J_{n+1, n+2}^{\prime}$ are the Jacobian of $f_{n+1, n+2}$ with respect to $y_{n+1, n+2}$ and $y_{n+1, n+2}^{\prime}$, respectively. The implementation is started with the lowest order of 2-point BBDF, i.e. order 3. As the initial conditions only provide the values for $y_{n-2}$ and $y_{n-2}^{\prime}$, the values of $y_{n-1}, y_{n}, y_{n-1}^{\prime}$ and $y_{n}^{\prime}$ are needed in implementing the 2-point BBDF of order 3. Therefore, the sequential direct second order Euler method is used at the initial stage of integration. Subsequently, the following steps are carried out;

Step 1: $\boldsymbol{P}$ : the predicted values of $y_{n+1, n+2}^{(i-1)}$ and $y_{n+1, n+2}^{(i-1)}$ are computed by using the predictor formula; Step 2: $\boldsymbol{E}$ : the predicted values are used to find $f_{n+1, n+2}^{(i-1)}$; Step 3: $\boldsymbol{C}$ : the iteration matrices in (26) and (27) are applied to find the increments of $e_{n+1, n+2}^{(i)}$ and $e_{n+1, n+2}^{\prime(i)}$; Step 4: $\boldsymbol{E}$ : the corrected values of $y_{n+1, n+2}^{(i)}$ and $y_{n+1, n+2}^{(i)}$ are used to evaluate the values of $f_{n+1, n+2}^{(i)}$; Step 5: repeat steps 3 and 4 .

We used two stages of the Newton iteration, i.e. $i=$ 1,2 . After the second iteration, the local truncation error $L T E_{k-1}$ of order $k, k=3,4,5$ are estimated. These $L T E_{k-1}$ are used to determine the order for the next integration step. The estimation of $L T E_{k-1}$ is given by:

$$
L T E_{k-1}=\left|y_{n+2}^{(k)}-y_{n+2}^{(k-1)}\right| .
$$

Thus, if the method of order 3 is used, the $L T E_{2}$ is approximated by the difference of $y_{n+2}$ from 2-point BBDF of order 2 and 3 . All the three LTEs are calculated and the highest will determine the order for the next integration step. The $L T E_{k-1}, k=3,4,5$ are given by,

$$
\begin{gathered}
\operatorname{LTE}_{2}=\left|\frac{33}{70} y_{n+1}-\frac{44}{35} y_{n}+\frac{11}{10} y_{n-1}-\frac{11}{35} y_{n-2}-\frac{11}{70} h^{2} f_{n+2}\right|, \\
\operatorname{LTE}_{3}=\left|\frac{142}{315} y_{n+1}-\frac{472}{315} y_{n}+\frac{28}{15} y_{n-1}-\frac{328}{315} y_{n-2}+\frac{2}{9} y_{n-3}-\frac{8}{105} h^{2} f_{n+2}\right| \\
\operatorname{LTE}_{4}=\mid \frac{137}{315} y_{n+1}-\frac{63157}{36540} y_{n}+\frac{8494}{3045} y_{n-1}-\frac{42059}{18270} y_{n-2} \\
+\frac{1781}{1827} y_{n-3}-\frac{137}{812} y_{n-4}-\frac{137}{3045} h^{2} f_{n+2} \mid
\end{gathered}
$$

\section{RESULTS AND DISCUSSION}

To validate the competency of the proposed variable order scheme, the numerical performances of variable order 2-point BBDF method is compared with single order 2-point BBDF (order 3, 4, 5). All 2-point BBDF codes are written in $\mathrm{C}++$ language. All problems are demonstrated in the interval $x=[0,10]$. The following abbreviations used in the tables indicates the following;
$\mathrm{H}$ : Step size (specified by user); voвbDF : variable order 2-point BBDF; O3 : 2-point BBDF of order 3; O4 : 2-point BBDF of order $4 ; \mathrm{O} 5: 2$-point BBDF of order 5 ; MAXE : Maximum error attained; AVE : Average error attained; TIME : Computation time in second.

The maximum error is calculated as follows:

$$
\operatorname{MAXE}=\max _{1 \leq i \leq S T E P}\left(\max _{1 \leq i \leq N}\left(e_{i}\right)_{t}\right),
$$

where $\left(e_{i}\right)_{t}=\mid \frac{\left(y_{i}\right)_{t}-\left(y\left(x_{i}\right)\right)_{t}}{A+B\left(y\left(x_{i}\right)\right)_{t}}$. As two approximations are given simultaneously, $t=1$ and 2 equivalents to first and second solutions, respectively. $\left(y\left(x_{i}\right)\right)_{t}$ is the $t$-th component of the exact solution and $\left(y_{i}\right)_{t}$ is the $t$-th component of computed solution at $x_{i}, N$ is the number of equations in the system and STEP is the total number of steps. Mixed error test is used where $A=1, B=1$.

Problem 1: Fang et al. (2009),

$$
\begin{gathered}
y_{1}^{\prime \prime}=-25 y_{1}-\varepsilon\left(y_{1}^{2}+y_{2}^{2}\right)+\varepsilon \varphi_{1}(x), \quad y_{2}^{\prime \prime}=-25 y_{2}-\varepsilon\left(y_{1}^{2}+y_{2}^{2}\right)+\varepsilon \varphi_{2}(x), \\
\varphi_{1}(x)=1+\varepsilon^{2}+2 \varepsilon \sin \left(5 x+x^{2}\right)+2 \cos \left(x^{2}\right)+\left(25-4 x^{2}\right) \sin \left(x^{2}\right), \\
\varphi_{2}(x)=1+\varepsilon^{2}+2 \varepsilon \sin \left(5 x+x^{2}\right)-2 \sin \left(x^{2}\right)+\left(25-4 x^{2}\right) \cos \left(x^{2}\right), \\
y_{1}(0)=1, \quad y_{1}^{\prime}(0)=0, \quad y_{2}(0)=\varepsilon, \quad y_{2}^{\prime}(0)=5,
\end{gathered}
$$

where $\varepsilon$ is equal to $10^{-3}$ and the exact solutions are given as $y_{1}(x)=\cos (5 x)+\varepsilon \sin \left(x^{2}\right)$ and $y_{2}(x)=\sin (5 x)+\varepsilon \cos$ $\left(x^{2}\right)$. By comparing the results of variable order 2-point BBDF and single order 2-point BBDF methods, the variable order scheme gives lowest maximum and average error. Although the improvement in maximum error is not much different than single order methods, it is shown that the variable order scheme is capable to give better approximation compared to single order methods (Table 3).

Problem 2: Lambert and Watson (1976),

$$
\begin{aligned}
& y_{1}^{\prime \prime}=-\lambda^{2} y_{1}+f^{\prime \prime}(x)+\lambda^{2} f(x), \quad y_{2}^{\prime \prime}=-\lambda^{2} y_{2}+f^{\prime \prime}(x)+\lambda^{2} f(x), \\
& y_{1}(0)=a+f(0), \quad y_{1}^{\prime}(0)=f^{\prime}(0), \\
& y_{2}(0)=f(0), \quad y_{2}^{\prime}(0)=\lambda a+f^{\prime}(0),
\end{aligned}
$$

where $f(x)$ is chosen to be $e^{-0.05 x}$, whereas the parameters $a$ and $\lambda$ are equivalent to 20 and 0.1 , respectively. The exact solutions are $y_{1}(x)=a \cos (\lambda x)+f(x)$ and $y_{2}(x)=$ $a \sin (\lambda x)+f(x)$. As the step size decreases, the variable order 2-point BBDF gives least maximum and average error. Improvement in accuracy for variable order scheme is due to the changing of order mechanism which is depend on LTE. At step size $10^{-2}$, the 2-point BBDF of order 4 has least maximum and average error. It can also be seen that the variable order 2-point BBDF has largest maximum error 
TABLE 3. Numerical result for Problem 1

\begin{tabular}{ccccc}
\hline $\mathrm{H}$ & METHOD & MAXE & AVE & TIME \\
\hline \multirow{4}{*}{$10^{-2}$} & VOBBDF & $1.6644 \mathrm{E}-03$ & $6.2225 \mathrm{E}-04$ & 0.004777 \\
& O5 & $3.6701 \mathrm{E}-03$ & $1.5501 \mathrm{E}-03$ & 0.004913 \\
& O4 & $2.3996 \mathrm{E}-03$ & $9.6153 \mathrm{E}-04$ & 0.003470 \\
& O3 & $2.3185 \mathrm{E}-03$ & $1.7790 \mathrm{E}-03$ & 0.003271 \\
\hline \multirow{4}{*}{$10^{-3}$} & VOBBDF & $1.6696 \mathrm{E}-05$ & $6.1271 \mathrm{E}-06$ & 0.047174 \\
& O5 & $3.6745 \mathrm{E}-05$ & $1.3616 \mathrm{E}-05$ & 0.034346 \\
& O4 & $2.3969 \mathrm{E}-05$ & $8.8273 \mathrm{E}-06$ & 0.032382 \\
$10^{-4}$ & O3 & $2.3245 \mathrm{E}-05$ & $1.7060 \mathrm{E}-05$ & 0.031982 \\
& VOBBDF & $1.6764 \mathrm{E}-07$ & $6.1402 \mathrm{E}-08$ & 0.469456 \\
& O5 & $3.6746 \mathrm{E}-07$ & $1.3441 \mathrm{E}-07$ & 0.326335 \\
& O4 & $2.3977 \mathrm{E}-07$ & $8.7929 \mathrm{E}-08$ & 0.321272 \\
$10^{-5}$ & O3 & $2.3256 \mathrm{E}-07$ & $1.7292 \mathrm{E}-07$ & 0.325334 \\
& VOBBDF & $2.1612 \mathrm{E}-07$ & $4.8313 \mathrm{E}-08$ & 4.716317 \\
& O5 & $2.1699 \mathrm{E}-07$ & $4.9141 \mathrm{E}-08$ & 3.251728 \\
& O4 & $5.1404 \mathrm{E}-07$ & $1.1700 \mathrm{E}-07$ & 3.224124 \\
& O3 & $1.4518 \mathrm{E}-06$ & $6.5668 \mathrm{E}-07$ & 3.243763 \\
\hline
\end{tabular}

because the variable order starts with order 3 . In fact, the 2-point BBDF of order 3 also has the highest average error. Although the proposed method gives largest maximum error, the average error become smaller. As the step size decreases, it shows that the variable order scheme improves the accuracy (Table 4).

Problem 3: Jator and Li (2009)

$$
\begin{aligned}
& L q^{\prime \prime}(t)+R q^{\prime}(t)+\left(\frac{1}{C}\right) q=E(t), \\
& q(0)=0, \quad i(0)=0 .
\end{aligned}
$$

This is the linear ODEs for $L R C$ series circuit. The notations $L, C$, and $R$ indicates the inductance, capacitance and resistance, respectively. The parameter $q(t)$ is the instantaneous charge at the time $t, E(t)$ is the voltage, and $i(t)$ is the current. The problem is solved with $L=1, R=$ 20, $C=0.005$, and $E(t)=150$. The theoretical solution is $q(t)=\frac{3}{4}\left(1-e^{-10 t}(\cos (10 t)+\sin (10 t))\right)$. From Table 5, it is observed that variable order 2-point BBDF has lowest maximum and average error compared to single order 2-point BBDF methods.

TABLE 4. Numerical result for Problem 2

\begin{tabular}{ccccc}
\hline $\mathrm{H}$ & METHOD & MAXE & AVE & TIME \\
\hline \multirow{4}{*}{$10^{-2}$} & VOBBDF & $8.5902 \mathrm{E}-03$ & $2.0453 \mathrm{E}-03$ & 0.001184 \\
& O5 & $6.2887 \mathrm{E}-03$ & $2.7437 \mathrm{E}-03$ & 0.002384 \\
& O4 & $5.0390 \mathrm{E}-03$ & $1.6928 \mathrm{E}-03$ & 0.001012 \\
& O3 & $8.2158 \mathrm{E}-03$ & $4.1048 \mathrm{E}-03$ & 0.000894 \\
\hline \multirow{4}{*}{$10^{-3}$} & VOBBDF & $2.8100 \mathrm{E}-05$ & $9.5946 \mathrm{E}-06$ & 0.011453 \\
& O5 & $7.7805 \mathrm{E}-05$ & $2.2195 \mathrm{E}-05$ & 0.010420 \\
& O4 & $5.0828 \mathrm{E}-05$ & $1.4204 \mathrm{E}-05$ & 0.008872 \\
& O3 & $3.9927 \mathrm{E}-05$ & $2.6833 \mathrm{E}-05$ & 0.008606 \\
$10^{-4}$ & VOBBDF & $3.5572 \mathrm{E}-07$ & $9.6452 \mathrm{E}-08$ & 0.114546 \\
& O5 & $7.7976 \mathrm{E}-07$ & $2.1210 \mathrm{E}-07$ & 0.088663 \\
& O4 & $5.0862 \mathrm{E}-07$ & $1.3805 \mathrm{E}-07$ & 0.093647 \\
& O3 & $4.8410 \mathrm{E}-07$ & $2.6738 \mathrm{E}-07$ & 0.085900 \\
\hline \multirow{4}{*}{$10^{-5}$} & VOBBDF & $5.3018 \mathrm{E}-09$ & $1.6123 \mathrm{E}-09$ & 1.148658 \\
& O5 & $8.3788 \mathrm{E}-09$ & $2.7462 \mathrm{E}-09$ & 0.869764 \\
& O4 & $1.1567 \mathrm{E}-08$ & $3.5577 \mathrm{E}-09$ & 0.870925 \\
& O3 & $2.8458 \mathrm{E}-08$ & $1.5899 \mathrm{E}-08$ & 0.890549 \\
\hline
\end{tabular}


TABLE 5. Numerical result for Problem 3

\begin{tabular}{ccccc}
\hline $\mathrm{H}$ & METHOD & MAXE & AVE & TIME \\
\hline \multirow{4}{*}{$10^{-2}$} & VOBBDF & $9.4043 \mathrm{E}-03$ & $1.3948 \mathrm{E}-04$ & 0.000489 \\
& O5 & $1.5422 \mathrm{E}-02$ & $2.1420 \mathrm{E}-04$ & 0.001839 \\
& O4 & $1.2100 \mathrm{E}-02$ & $1.7632 \mathrm{E}-04$ & 0.000565 \\
& O3 & $1.1910 \mathrm{E}-02$ & $1.7476 \mathrm{E}-04$ & 0.000397 \\
\hline \multirow{4}{*}{$10^{-3}$} & VOBBDF & $1.0443 \mathrm{E}-04$ & $1.5845 \mathrm{E}-06$ & 0.004566 \\
& O5 & $2.2434 \mathrm{E}-04$ & $3.4050 \mathrm{E}-06$ & 0.005498 \\
& O4 & $1.4856 \mathrm{E}-04$ & $2.2536 \mathrm{E}-06$ & 0.003891 \\
& O3 & $1.4447 \mathrm{E}-04$ & $2.1925 \mathrm{E}-06$ & 0.003719 \\
\hline \multirow{4}{*}{$10^{-4}$} & VOBBDF & $1.0534 \mathrm{E}-06$ & $1.5959 \mathrm{E}-08$ & 0.062477 \\
& O5 & $2.3131 \mathrm{E}-06$ & $3.5044 \mathrm{E}-08$ & 0.039417 \\
& O4 & $1.5111 \mathrm{E}-06$ & $2.2894 \mathrm{E}-08$ & 0.038098 \\
$10^{-5}$ & O3 & $1.4675 \mathrm{E}-06$ & $2.2261 \mathrm{E}-08$ & 0.037034 \\
& OOBBDF & $1.0534 \mathrm{E}-08$ & $5.6940 \mathrm{E}-10$ & 0.452739 \\
& O5 & $2.3192 \mathrm{E}-08$ & $8.7165 \mathrm{E}-10$ & 0.379677 \\
& O4 & $1.5157 \mathrm{E}-08$ & $1.2482 \mathrm{E}-09$ & 0.367684 \\
& O3 & $1.4630 \mathrm{E}-08$ & $2.0207 \mathrm{E}-09$ & 0.379378 \\
\hline
\end{tabular}

TABLE 6. Numerical result for Problem 4

\begin{tabular}{ccccc}
\hline $\mathrm{H}$ & & MAXE & AVE & TIME \\
\hline \multirow{3}{*}{$10^{-2}$} & VOBBDF & $1.1946 \mathrm{E}-01$ & $4.5480 \mathrm{E}-04$ & 0.000860 \\
& O5 & NC & NC & NC \\
& O4 & $3.3204 \mathrm{E}-01$ & $3.0505 \mathrm{E}-03$ & 0.000758 \\
& O3 & $2.4045 \mathrm{E}-01$ & $6.4248 \mathrm{E}-04$ & 0.000582 \\
\hline \multirow{3}{*}{$10^{-3}$} & VOBBDF & $3.2291 \mathrm{E}-03$ & $1.3454 \mathrm{E}-03$ & 0.010015 \\
& O5 & $2.3145 \mathrm{E}-03$ & $4.4723 \mathrm{E}-04$ & 0.015149 \\
& O4 & $2.1475 \mathrm{E}-03$ & $9.7396 \mathrm{E}-04$ & 0.006031 \\
$10^{-4}$ & O3 & $3.7937 \mathrm{E}-03$ & $1.4612 \mathrm{E}-03$ & 0.005719 \\
& VOBBDF & $1.7732 \mathrm{E}-05$ & $2.1583 \mathrm{E}-06$ & 0.078789 \\
& O5 & $3.8953 \mathrm{E}-05$ & $5.9952 \mathrm{E}-06$ & 0.059315 \\
& O4 & $2.5492 \mathrm{E}-05$ & $3.9297 \mathrm{E}-06$ & 0.056494 \\
$10^{-5}$ & O3 & $2.4698 \mathrm{E}-05$ & $4.2301 \mathrm{E}-06$ & 0.056253 \\
\hline & VOBBDF & $1.7784 \mathrm{E}-07$ & $2.7387 \mathrm{E}-08$ & 0.736852 \\
& O5 & $3.9138 \mathrm{E}-07$ & $6.0254 \mathrm{E}-08$ & 0.566079 \\
& O4 & $2.5530 \mathrm{E}-07$ & $3.9316 \mathrm{E}-08$ & 0.565092 \\
\hline
\end{tabular}

$* \mathrm{NC}=$ Not Converge

Problem 4: Denk (1993)

$$
\begin{aligned}
& y(x)+\kappa^{2} y(x)=\kappa^{2} x, \\
& y(0)=10^{-5}, y^{\prime}(0)=1-10^{-5} \kappa=\frac{\cos (\kappa)}{\sin (\kappa)}, \kappa=314.16
\end{aligned}
$$

The exact solution for this problem is $y(x)=x+10^{-5}$ $\left(\cos (\kappa x)-\frac{\cos (\kappa)}{\sin (\kappa)} \sin (\kappa x)\right)$. In Table 6, the variable order 2-point BBDF gives better approximation at the step size $10^{-2}$. Surprisingly, the 2-point BBDF of order 5 fails to converge at step size of $10^{-2}$. Although the average error of variable order 2-point BBDF deteriorates at step size $10^{-3}$, the proposed method is capable to obtain smaller maximum and average error when the step size is reduced to $10^{-4}$.

\section{CONCLUSION}

The 2-point BBDF of order 3, 4, and 5 has been implemented in single code with strategy of variable order scheme for solving second order ODEs directly. The LTE in the code is utilized to determine the order for next integration. Although most of the numerical results are comparable, it can be seen that the variable order 2-point BBDF has an advantage in accuracy especially when using finer step size. Since the numerical solution of ODEs using single 
order methods is tedious, the variable order scheme can be an alternative solver.

\section{ACKNOWLEDGEMENTS}

The research was partially supported by STIRF grant 0153AA-C82 from Universiti Teknologi PETRONAS.

\section{REFERENCES}

Chawla, M.M. \& Sharma, S.R. 1985. Families of three-stage third order Runge-Kutta-Nyström methods for $y^{\prime \prime}=f\left(x, y, y^{\prime}\right)$. The Journal of the Australian Mathematical Society 26: 375-386.

Chien, L.K., Din, U.K.S. \& Ahmad, R.R. 2018. Solution of third order ordinary differential equation using improved block hybrid collocation method. Sains Malaysiana 47(9): 2179-2186.

Denk, G. 1993. A new numerical method for the integration of highly oscillatory second-order ordinary differential equations. Applied Numerical Mathematics 13: 57-67.

Fang, Y., Song, Y. \& Wu, X. 2009. A robust trigonometrically fitted embedded pair for perturbed oscillators. Journal of Computational and Applied Mathematics 225: 347-355.

Fatunla, S.O. 1991. Block method for second order ODEs. International Journal of Computer Mathematics 41: 55-63.

Gear, C.W. 1967. The numerical integration of ordinary differential equations. Mathematics of Computation 21: 146-156.

Henrici, P. 1962. Discrete Variable Methods in Ordinary Differential Equations. New York: John Wiley and Sons.

Ibrahim, Z.B., Othman, K.I. \& Suleiman, M.B. 2007. Implicit r-point block backward differentiation formula for solving first-order stiff ODEs. Applied Mathematics and Computation 186: 558-565.

Ibrahim, Z.B., Othman, K.I. \& Suleiman, M.B. 2012. 2-Point block predictor-corrector of backward differentiation formulas for solving second order ordinary differential equations directly. Chiang Mai Journal of Science 39(3): 502-510.

Ismail, F., Ahmad, S.Z., Jikantoro, Y.D. \& Senu, N. 2018. Block hybrid method with trigonometric-fitting for solving oscillatory problems. Sains Malaysiana 47(9): 2223-2230.

Ismail, F., Hussain, K. \& Senu, N. 2016. A sixth-order RKFD method with four-stage for directly solving special fourthorder ODEs. Sains Malaysiana 45(11): 1747-1754.

Jator, S.N. \& Li, J. 2009. A self-starting linear multistep method for a direct solution of the general second-order initial value problem. International Journal of Computer Mathematics 86(5): 827-836.

Jator, S.N. 2010. Solving second order initial value problems by a hybrid multistep method without predictors. Applied Mathematics and Computation 217: 4036-4046.

Jator, S.N., Akinfenwa, A.O., Okunuga, S.A. \& Sofoluwe, A.B. 2013. High-order continuous third derivative formulas with block extensions for $y^{\prime \prime}=f\left(x, y, y^{\prime}\right)$. International Journal of Computer Mathematics 90(9): 1899-1914.

Kambo, N.S., Jain, R.K. \& Goel, R. 1983. A fourth order method for $y^{\prime \prime}=f\left(x, y, y^{\prime}\right)$. Journal of Computational and Applied Mathematics 9: 81-90.
Lambert, J.D. \& Watson, I.A. 1976. Symmetric multistep methods for periodic initial value problems. IMA Journal of Applied Mathematics 18: 189-202.

Milne, W.E. 1953. Numerical Solution of Differential Equations. New York: John Wiley \& Sons.

Sagir, A.M. 2013. An accurate computation of block hybrid method for solving stiff ordinary differential equations. World Academy of Science, Engineering and Technology 7: 321-324.

Sesappa Rai, A. \& Ananthakrishnaiah, U. 1996. Additive parameters methods for the numerical integration of $y^{\prime \prime}=f$ $\left(t, y, y^{\prime}\right)$. Journal of Computational and Applied Mathematics 67: 271-276.

Waeleh, N. \& Majid, Z.A. 2017. Numerical algorithm of block method for general second order odes using variable step size. Sains Malaysiana 46(5): 817-824.

Zainuddin, N., Ibrahim, Z.B. \& Othman, K.I. 2014. Diagonally implicit block backward differentiation formula for solving linear second order ordinary differential equations. AIP Conference Proceedings 1621: 69-75.

Zarina Bibi Ibrahim

Department of Mathematics

Faculty of Science

Universiti Putra Malaysia

43400 UPM Serdang, Selangor Darul Ehsan

Malaysia

Zarina Bibi Ibrahim \& Mohamed Suleiman

Institute for Mathematical Research

Universiti Putra Malaysia

43400 UPM Serdang, Selangor Darul Ehsan

Malaysia

Nooraini Zainuddin*

Department of Fundamental and Applied Sciences

Universiti Teknologi PETRONAS (UTP)

32610 Bandar Seri Iskandar, Perak Darul Ridzuan

Malaysia

Khairil Iskandar Othman

Department of Mathematics

Faculty of Computer and Mathematical Sciences

Universiti Teknologi MARA

40450 Shah Alam, Selangor Darul Ehsan

Malaysia

Iskandar Shah Mohd Zawawi

Faculty of Computer and Mathematical Sciences

Universiti Teknologi MARA

Seremban Campus

70300 Seremban, Negeri Sembilan Darul Khusus

Malaysia

*Corresponding author; email: aini_zainuddin@utp.edu.my

Received: 1 February 2019

Accepted: 7 May 2019 